\title{
StudioClio espaço de interações culturais: um olhar sobre a cultura, a arte e a gastronomia $^{1}$
}

Ana Méri Zavadil Machado²

\section{Resumo}

Este artigo integra estudos sobre Espaços Não Institucionais de Arte. O StudioClio é um espaço que enriquece a paisagem cultural de Porto Alegre. Multidisciplinar, atua em diversos segmentos: artes visuais, música, literatura, cinema, teatro, filosofia, história, moda e gastronomia. Neste texto, busca-se realizar um estudo sobre cultura, arte e gastronomia, tendo como foco duas atividades realizadas no StudioClio: o Almoço Cultural e o Banquete Cultural.

Palavras-chave: cultura, arte, gastronomia, Almoço Cultural, Banquete Cultural.

\begin{abstract}
This article integrates studies about Spaces Non-Institutional of Art. StudioClio is a space that enriches the cultural scenery of Porto Alegre. As it is a Multidisciplinary place, it acts in several segments: visual arts, music, literature, cinema, theater, philosophy, history, fashion and gastronomy. This article intends to study about culture, art and gastronomy, focusing on two activities carried out at StudioClio: Cultural Lunch and Cultural Banquet.
\end{abstract}

Keywords: culture, art, gastronomy, Cultural Banquet, Cultural Lunch.

\section{A palavra Cultura: origem e significado}

O StudioClio é um lugar de diversificados acontecimentos, no campo cultural de Porto Alegre, que abrange diferentes atividades por meio de linguagens artísticas e de suas relações com outros campos de conhecimento.

Para este estudo, é importante resgatar alguns dos significados históricos associados ao conceito de cultura e a suas implicações com a arte a partir de alguns autores das áreas de sociologia, antropologia e história da arte, para, depois, identificar os elos entre arte e gastronomia nas atividades: Banquete Cultural e Almoço Cultural, realizadas no StudioClio, atividades situadas entre-territórios, ou seja, entre arte, cultura e gastronomia.

\footnotetext{
${ }_{1}^{1}$ Este artigo faz parte de minha pesquisa de mestrado que analisa os espaços culturais não institucionais em Porto Alegre

${ }^{2}$ Mestranda em Artes Visuais, bolsista da CAPES, desenvolve pesquisa vinculada à linha de pesquisa de Arte e Cultura, no Programa de Pós Graduação em Artes Visuais da UFSM, sob a orientação da Professora Dra. Blanca Brites (UFRGS).
} 
A palavra cultura, desde o século XVII, já fazia parte do vocabulário francês. Vinda do latim, cultura significa cuidado dispensado ao campo ou ao gado. No século XIII, já aparecia como "parcela de terra cultivada" (CUCHE, 2002, p.19). Na metade do século XVI, aparece no sentido figurado como "cultura de uma faculdade, isto é, o fato de trabalhar para desenvolvê-la" (CUCHE, 2002, p.19). No século XVIII, começa a se impor, no sentido figurado, e entra para o Dicionário da Academia Francesa (edição de 1718). No entanto, aparecia sempre com outra palavra complementar: cultura das letras, cultura das ciências, etc. Com o passar do tempo, esse complemento foi abolido e cultura passa a designar a formação e a educação do espírito.

O sentido da palavra cultura, na França, aproximou-se de outra palavra: civilização. Apesar de terem as mesmas concepções fundamentais, a primeira, trata dos progressos individuais e a segunda dos coletivos. Para os filósofos, civilização significa progresso e melhoria das instituições, legislações e da educação no sentido universal de estender-se a todos os povos. Já Kultur, no sentido figurado, aparece no século XVIII, na língua alemã, mas significa o oposto da noção de civilização na França, pois ela diz respeito somente ao povo alemão e daquilo que o distinguia dos outros.

Teixeira Coelho explica que a cultura á algo específico de um povo, conforme a noção de civilização do povo alemão, ou seja:

A cultura de um lugar não deveria ser vista como a soma de tudo, mas apenas do específico daquele lugar: não o universal, mas o particular; cultura não era o todo de todos, mas o relativo a um grupo, com a implicação que cada cultura revestia-se de um atributo a ela relativo. (COELHO, 2008, p.21).

De acordo com Roger Taylor, houve uma divisão histórica por volta do século XVIII, a partir do surgimento de dois fatos: o domínio da burguesia sobre a aristocracia rural e o aparecimento da ciência; esses dois fatos fizeram cair por terra hábitos antigos e deram início a uma nova maneira de ver a vida. Esse acontecimento acarretou um retorno da aristocracia para partes do antigo sistema ainda não atingidas e as transformou em novas formas de oposição à burguesia. "A arte foi uma invenção da aristocracia." (TAYLOR, 2005, p.60). O novo conceito de arte veio dessa transformação, de uma parte dessa velha forma, em objeto de culto irracional. "Quando a burguesia assimila e transforma o estilo de vida da aristocracia, atividades burguesas, como a pintura, os escritos, etc., que não seriam considerados arte pelos critérios da aristocracia, passa a ser". (TAYLOR, 2005, p.63). A arte fica dependente da ascensão da burguesia, o que a torna suscetível a mudanças ligadas à tecnologia e ao modo social como é veiculada. A arte como se conhece na contemporaneidade é o resultado de vários processos. É uma 
forma de vida, um sistema conceitual dentro da estrutura burguesa e envolve o juízo. A área social de onde vem é que lhe dá o status de arte.

A manutenção da tradição da arte e o seu crescimento provêm dos processos sociais dentro da classe média ou da burguesia. A experiência cultural, que é imposta, é chamada alta cultura por ser bem aceita e também parte integrante da vida burguesa que não está no cotidiano das massas, embora exija conhecimento nesse campo para tornar o sucesso na academia possível.

A ideologia da alta cultura do século XX afirma que a arte é universal e, a exemplo disso, objetos classificados como pertencentes aos museus e de interesse etnográfico foram parar nas galerias de arte.

As pessoas são educadas de acordo com a tradição na arte, principalmente a contemporânea enquanto os processos sociais são negócios ou indústrias dessa sociedade, que envolvem planejamentos sociais.

A palavra cultura analisada com outra raiz: coulter é considerada uma cognata de cultura, cujo significado é "a lâmina do arado". Para Teixeira Coelho, essa definição é "estimulante" para os estudos de cultura e de políticas culturais. Só que ele acha conveniente guardar essa "imagem do arado" para algo maior do que a cultura: a arte. 0 entendimento da cultura, tendo como ênfase as artes refinadas, ou seja, as belas artes (termo antigo usado para referir-se a artes ou obras do espírito) deve ter senso crítico para que seja realmente cultural. Então, "a lâmina do arado" retorna: "A lâmina afiada que penetra nesse campo e o corta e revolve, pondo para cima o que estava embaixo e vice-versa". (COELHO, 2008, p.18) A capacidade de diferenciar entre uma coisa e outra com rapidez e senso crítico agudo é importante em um mundo, pois a informação em demasia prejudica qualquer reflexão.

Francis Bacon, filósofo inglês, escreveu sobre cultura e adubamento dos espíritos em uma tessitura sugestiva entre esterco e elevação espiritual. Parafraseando o autor que diz sobre a primeira ideia que surge dessa premissa da cultura como adubo é a de processo que está contido nela, ou seja, o estrume é o elemento ativo, mas ele em si não é nada, ele mesmo é outra coisa, e outra coisa que resulta de um processo cujas partes têm a mesma natureza verificada no conjunto. A questão principal é a cultura como atividade. 
O antropólogo Franz Boas (1858-1942) estabelece algumas proposições vistas hoje no relativismo cultural pesquisadas pelos etnólogos e que aparecem nas atividades do StudioClio que resgata a cultura de povos antigos para dar uma nova interpretação nos almoços e banquetes. Boas diz que:

[...] cada cultura tem um valor próprio a ser reconhecido, um estilo específico que se manifesta na língua, nas crenças, nos costumes e na arte e que veicula um espírito próprio (a identidade), cabendo ao etnólogo estudar as culturas (não a Cultura) e, mais do que verificar em que consiste uma dada cultura, apreender o elo que une um indivíduo a uma cultura. (Apud COELHO, 2008, p.22)

Logo, a cultura toma para si o significado de conjunto de padrões de comportamento, de crenças, de conhecimentos e dos costumes que particularizam um grupo social. Pode-se pensar ainda em forma ou etapa de evolução e de valores tanto intelectuais como morais e espirituais de um lugar ou época específica.

Pierre Bourdieu (1930-2002), em suas pesquisas sobre capital cultural, no livro L'amour de L'art, de 1969, em coautoria com Alan Darbel diz que o amor pela arte é fruto de aprendizado e socialização. A partir da sua extensa pesquisa, passa-se a falar de um público, no plural, com competência e repertórios diferenciados. Por esse motivo, a origem do conceito de capital cultural está baseada em "diplomas e origem familiar" (BOURDIEU, 2007, p. 71). Isso significa que se recebe da família e da escola conhecimentos e incentivos para a prática cultural. "A obra de arte considerada bem simbólico não existe como tal a não ser para quem detenha os meios de apropriar-se dela, ou seja, decifrá-la". (BOURDIEU, 2007, p.71). Portanto, a apropriação do capital artístico está intrinsecamente relacionada à decifração das obras de arte que são apresentadas diante de determinadas sociedades em um referido espaço/tempo. Os bens culturais, da gastronomia até a música, passando pelo cinema ou teatro, são objetos de apreensão que podem abarcar desde uma simples sensação até o deleite erudito, uma vez que se tenha noção da tradição e das regras do jogo. Os freqüentadores do StudioClio tem o perfil de um público especializado que teve na escola e nas origens familiares uma educação que permite a aproximação com as atividades culturais lá apresentadas, confirmando as pesquisas de Bourdieu.

\section{StudioClio: espaço de arte e cultura}

Os espaços culturais visam a uma aproximação com um público capaz de apreciar a arte em suas diferentes demonstrações e entrelaçamentos. Como modelo de espaço cultural, o StudioClio detém um público elitizado para a fruição de suas atividades artísticas, 
constituído por artistas, estudantes e intelectuais que estão em constante busca por novos saberes. Cada um procura atividades em uma área específica, porém as permeabilidades possíveis entre uma e outra instauram diálogos, principalmente, devido aos desvios nos modos tradicionais de apresentação dos programas culturais.

O StudioClio - Instituto de Arte e Humanismo - está situado na Cidade Baixa, bairro que se destaca pela sua efervescente atividade de bares, cafés, restaurantes, além de abrigar outros espaços culturais, como a Associação Riograndense de Artes Plásticas Francisco Lisboa, a Fundação ECARTA e vários ateliês coletivos. Voltado ao conhecimento, é um espaço de estudo, de criação e de ensino que envolve múltiplas atividades com a intenção de trazer um novo olhar para as diferentes formas de expressão e formar um público cativo.

O espaço cultural tem como proposta atividades transdisciplinares que tratam de conteúdos da cultura universal. Os eventos de sua programação são elaborados por cientistas, artistas, escritores, estudantes e chefs e englobam as artes visuais, o cinema, o teatro, a filosofia, a história, a literatura, a moda, a música e a gastronomia apresentadas sob a forma de cursos, concertos, oficinas, exposições, shows, seminários, publicações e gastronomia por meio das atividades: Banquete Cultural e Almoço Cultural. As atividades desenvolvem-se uma invadindo o espaço da outra em uma relação de trocas e aproximações.

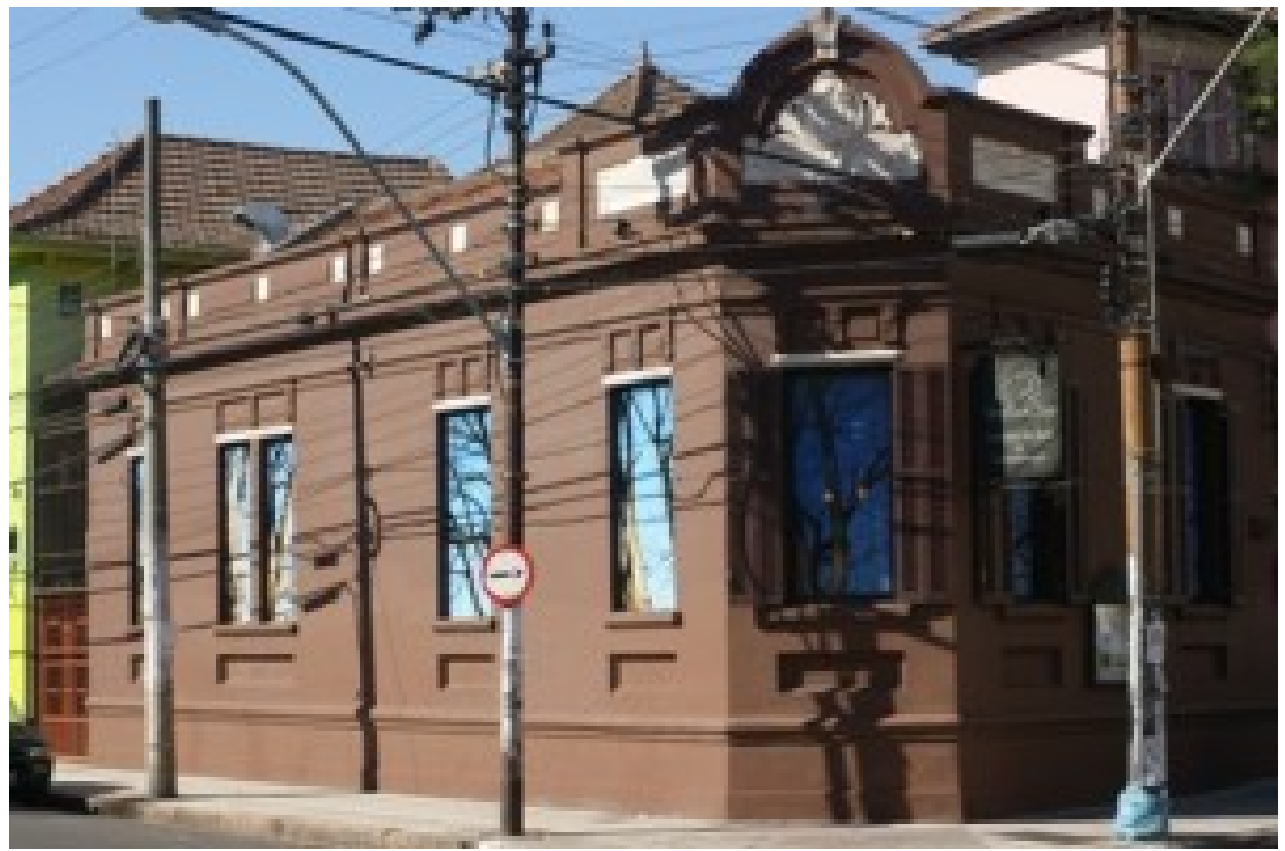

Figura 1: StudioClio, R. José do Patrocínio, 698 - Fone: (51) 32547200

Porto Alegre/RS/Brasil - CEP 90050-000 - Foto: Francisco Marshall 
O nome foi escolhido com base na deusa da História, chamada Clio, filha de Zeus e da Memória, e celebra a beleza da narrativa, simbolizando todas as expressões artísticas e intelectuais. Studio (studiolum) vem do gabinete renascentista. A conduta do StudioClio, voltada para a erudição e criação interdisciplinar, está como deseja a ciência e a cultura da contemporaneidade: híbrida, miscigenada e com trocas entre os campos de conhecimento.

O responsável pela concepção do espaço e da programação cultural é o Professor da UFRGS, classicista, Francisco Marshall, que fala a respeito de sua formação: "O classicista tem por meta social recuperar e tornar relevante a memória profunda da civilização, ampliando a noção de identidade cultural e os recursos disponíveis para a reflexão e a ação contemporânea". (MARSHALL, 2009) Ele está à frente de tudo o que acontece no StudioClio e atua como curador cultural, desde setembro de 2005, data da inauguração.

Questionado como surgiu esse espaço cultural Marshall explica:

O StudioClio complementa e enriquece a paisagem cultural de Porto Alegre com uma agenda de atividades originais e de alto nível em todos os campos da arte e do humanismo, com ênfase na memória cultural. Ele nasceu para ser um instituto transdisciplinar, aberto ao diálogo e à interação entre pessoas, épocas, gêneros e disciplinas, desburocratizado, acessível e confiável. Ele dinamiza a vida acadêmica e promove a criação artística. Sobretudo, o StudioClio oferece ao público a percepção de nossa dimensão cultural universal, por meio de diferentes comentários sobre o patrimônio cultural da humanidade, com nosso ponto de vista atual e brasileiro, latino americano. 'A ideia surgiu de uma percepção estratégica - a falta que faz um espaço desse tipo e os benefícios que pode produzir à sociedade'. (MARSHALL, 2009)

Ainda deve-se salientar que o prédio construído em 1924 sofreu mudanças entre 2004 e 2005. Ele é composto por um auditório de 53 lugares fixos e uma plateia baixa com possibilidades de adequação conforme a atividade que vai receber. O StudioClio também tem uma sala de concertos para 108 pessoas, uma de banquete para 58 pessoas, sala de aula com recursos audiovisuais de qualidade e um cinema digital ou clube de jazz com instrumentos acústicos. Além disso, tem um espaço, chamado Microgaleria de Arte Acessível, que se situa junto à recepção e tem como curadores a Professora da UFRGS Blanca Brites e o artista plástico e designer Leandro Selister. As exposições de arte contemporânea, realizadas nesse espaço, primam por pequenos formatos e preços acessíveis. O café está na parte frontal e abriga um espaço expositivo, no interior de seu ambiente, chamado Quadro Branco. 
A criatividade com que são apresentados os eventos suscita reflexões sobre os fenômenos artísticos e sobre a crença de que as verdadeiras obras de arte são dotadas de beleza universal, ou seja, essa beleza pode emocionar a todos os seres sensíveis, independentemente da cultura que possuem.

\section{Arte e Gastronomia: Banquete Cultural e Almoço Cultural}

A partir da programação periódica realizada pelo StudioClio, foram escolhidas duas para fazer um estudo mais significativo, trata-se da relação entre arte e gastronomia por meio do Banquete Cultural e do Almoço Cultural. Essas atividades são referenciais de gastronomia cultural na cidade de Porto Alegre e no Brasil.

Antes de falar de cada uma delas, é necessário retomar alguns antecedentes históricos sobre arte e gastronomia através da história da arte. A ação recíproca entre arte e alimento manifestou-se desde sempre nas relações sociais e culturais humanas, basta lembrar que os homens primitivos se reuniam ao redor do fogo para se alimentar.

Na história da alimentação e dos comportamentos alimentares, cruzam-se as histórias econômica, social e cultural de um povo: indicador do nível de vida, da identidade cultural e de segregação social. Pode-se citar o exemplo do pão, na França do Antigo Regime, em que o pão consumido pelas classes populares era o preto (pão bis ou brode) e pelas elites, o pão branco (pão de chapitre). A revolução decretou o brioche para todos, o que representou para a classe popular uma conquista social em detrimento do valor nutricional. Desse fato em diante, o pão tornou-se o alimento básico para o consumo das classes menos abastadas. Já a batata fez o caminho inverso, desprezada pela aristocracia até a Revolução, no século XIX, ela eleva-se socialmente.

Em Paris, no século XIX "a gastronomia se instala, sob a Revolução, nos restaurantes de luxo abertos pelos ex-chefs de cozinha das casas aristocráticas". (LE GOFF, 2005, p.183). A gastronomia torna-se símbolo de poder e ostentação.Tendo em vista a pobreza das classes inferiores, ela afirma o status da burguesia.

Os banquetes são acontecimentos registrados desde os mais remotos tempos na cultura grega e romana e a ação recíproca entre arte e alimento era uma manifestação cultural para unir arte e culinária, com a intenção de demonstrar a riqueza e o poder. Ao redor da mesa farta decidiam-se o destino de pessoas e nações.

A comida era apresentada em formas de esculturas de animais ou seres mitológicos para causar estranhamento, tudo na mais perfeita harmonia com músicos e artistas do teatro, 
uma verdadeira performance (a partir de um olhar contemporâneo) para impressionar os convidados e conquistar o poder por meio dos sentidos.

Ademais, pode-se pensar em outros episódios dentro da cronologia histórica que envolve arte e alimentos, um dos mais destacados é o Banquete (Platão), em que Sócrates discutiu com outros filósofos o gosto e traçou a filosofia ocidental. Na antiguidade, as pinturas dos frescos gregos e romanos eram cenas de banquetes; no Renascimento, destaca-se a Ceia de Leonardo da Vinci, a pintura barroca holandesa cheia de representações de naturezas mortas e as cenas em torno da mesa de Vermeer; Cezànne, Van Gogh e Gauguin trabalham arranjos de frutos e flores; a famosa cena de Manet: Dejeuneur sur I'herbe; no Modernismo, a invenção da comida dos Bistrôs e, na Arte Contemporânea, a comida é usada como matéria plástica: de Joseph Beyus a Artur Barrio, tudo é possível.

Para terminar esta análise ainda falta discutir dois termos: a gastronomia e a culinária. A gastronomia é um ramo que abrange a culinária, as bebidas e os materiais usados na alimentação, além dos aspectos culturais a ela associados. O gastrônomo (ou gourmet em francês) pode ser um cozinheiro, mas pode também ser a pessoa que se preocupa com o refinamento da alimentação. A gastronomia inclui não apenas a preparação dos alimentos, mas também a sua apresentação. É importante salientar que o vestuário, a música e a dança fazem parte do acompanhamento da refeição. A diferença entre os dois termos é que a culinária diz respeito à técnica de preparação dos alimentos enquanto a gastronomia tem um conceito mais alargado. O prazer de comer está na sua origem, e a associação de alimentos, cores e sabores faz o seu exotismo.

Como já foi visto, a gastronomia é uma cultura de tempos antigos e esteve acompanhada de grandes acontecimentos sociais e políticos, caminhando lado a lado na formação da Alta Cultura Ocidental.

Depois de esclarecidas as questões sobre cultura, arte, gastronomia, compreende-se melhor as atividades realizadas no StudioClio. Em primeiro lugar, os Banquetes Culturais. Eles acontecem uma vez por mês e tem o objetivo de trazer uma noite de prazeres e conhecimentos plenamente harmonizados. A experiência de convívio e o resgate da memória da cultura universal abrangem temas relevantes da história das artes e da humanidade. Um especialista do tema escolhido é convidado para fazer a conferência, em que ele situa o convidado no tempo e no espaço tematizados. Depois, é realizada uma exibição artística (que pode ser dramática, musical ou coreográfica) para ilustrar o assunto proposto, e o banquete, que tem o cardápio do período apresentado, é oferecido 
em uma releitura contemporânea, composto por entrada, prato principal, sobremesa e bebidas. A comida fica a cargo de um chef de cuisine que vai preparar tudo de acordo com o assunto da noite. A decoração e os aromas no ambiente trazem a complementação ideal para unir laços e tornar o ambiente fraterno. Muitos foram os Banquetes Culturais realizados desde 2005, entre eles: O Império Asteca (29/05/2009); Gauleses: o mundo de Asterix e Obelix (19/06/2009); Noites Áticas 2: Eros (28/01/2010), em que a arqueologia da história de Eros (tema preferido de artistas e poetas) foi apresentada por Marshall, com comentários de Donaldo Schüller e performance poética de Laura Medina. A gastronomia afrodisíaca ficou a cargo do chef César Sperotto. Os banquetes mexem com o imaginário por apresentarem verdadeiras encenações performáticas que tocam a sensibilidade dos participantes.

Em segundo lugar, destacam-se os Almoços Culturais. Essa atividade é realizada quinzenalmente, nas quartas-feiras, (das $12 \mathrm{~h} 20$ às 13h40) e um especialista ligado à área das artes (visuais, música, literatura, história, teatro ou arqueologia) ou da ciência é convidado para fazer uma palestra. É servida uma refeição temática com entrada, prato principal, sobremesa e bebidas. O ambiente é preparado para saborear conjuntamente a cultura, sob a forma do tema proposto, e a gastronomia. Por exemplo, enquanto se assiste à apresentação de Tiago Halewicz que mostra a coleção de obras do Museu Nacional de Varsóvia, pode-se almoçar um prato típico do lugar com novas releituras. (Almoço Cultural realizado no dia 16/12/2009). Nesse contexto, é possível encontrar confraternização e conhecimento em um ambiente agradável e com recursos de um Instituto que inova no campo cultural. O almoço é uma atividade cotidiana, em que o público acostumado a frequentar o StudioClio, se encontra por dois motivos: o social e o cultural, pois ali, certamente, estão apreciadores de boa comida e interessados em expandir seus conhecimentos sobre um tema específico.

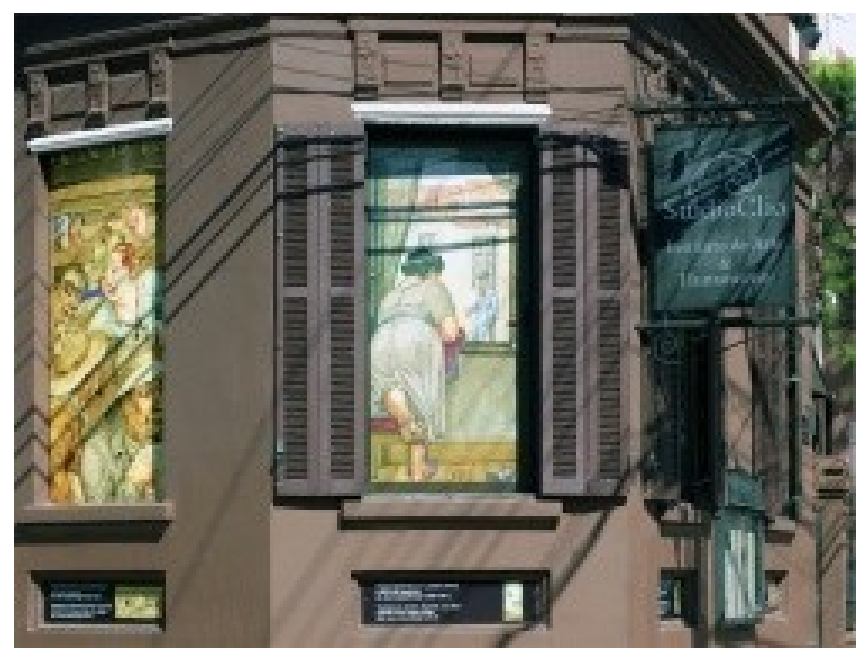

Figura 2: Fachada do StudioClio - Foto: Francisco Marshall 


\section{Considerações Finais}

Por fim, as tessituras entre a cultura, a arte e a gastronomia, que andam juntas desde os primórdios da evolução da humanidade, revelam-se nas atividades de um espaço não institucional de arte. O StudioClio foi alvo desta pesquisa como um desses espaços e mostra-se eficiente na sua tarefa de resgatar a memória da civilização nos diversos contextos históricos. O Banquete Cultural e o Almoço Cultural recuperam a História Clássica e entre o antigo e o contemporâneo o intuito é desenvolver o pensamento crítico.

\section{Referências}

BOURDIEU, Pierre. DARBEL, Alain. Obras culturais e disposição culta. In: amor pela arte: os museus de arte na Europa e seu público. Porto Alegre: Zouk, 2007, p.69-111.

COELHO, Teixeira. Nem tudo é cultura. In: A cultura e seu contrário. São Paulo: Iluminuras, 2008. p.17- 48.

CUCHE, Denys. Gênese social da palavra e da idéia de cultura. In: A Noção de cultura nas Ciências Sociais. Bauru: EDUSC, 2002, p.17-31.

LE GOFF, Jacques. A História Nova. São Paulo. Martins Fontes, 2005.

MARSHALL, Francisco. [Entrevista disponibilizada em 11 de maio de 2009, na Internet]1999.Disponívelem< http://wp.clicrbs.com.br/pedepagina/2009/11/05/ entrevista-com-francisco-marshall> Acesso em: 10/01/2010.

TAYLOR, Roger L. Corrigindo idéias equivocadas sobre arte e cultura. In: Arte inimiga do povo. São Paulo: Conrad, 2005, p.43-79. 